\title{
A Cloud based Solution for Online Examination Management in Education-An Architecture
}

\author{
Jewan Singh ${ }^{1}$, Vibhakar Mansotra ${ }^{2}$ \\ ${ }^{1}$ Research Scholar, School of Electrical Engineering, Department of IT, AMET University, India \\ ${ }^{2}$ Professor, Department of Computer Science \& IT, University of Jammu, India
}

\begin{abstract}
In this paper we attempt to show the applicability and usage of cloud computing in examination management in education. A cloud based solution is proposed to address the various issues pointed out by the researchers in the literature for adoption of online examination system in educational institutions. We also presented guidelines for managing existing resources for online examination management using open source cloud technologies.
\end{abstract}

Keywords: Online examination cloud, Openstack, VM virtual box, Virtual machines

\section{Introduction}

The use of ICTs in examination is a welcome innovation in curbing irregularities in traditional examination system. In order to gain benefits from technologies it is important to have an understanding of the benefits and drawbacks to their usage, as well as ensuring that these are implemented in ideal ways. The educational institutions face a wide range of challenges in implementing ICTs such as cost, lack of technical resources and resistance by key stakeholders to the implementation of system. Cloud-based system is emerging as an attractive method for providing examination services. It can reduce cost due to lower requirements of hardware and software and less need for onsite maintenance. The main purpose of this paper is to access the potential value of cloud computing as platform for online examination management in education. Authors in [1] and [2] pointed out the advantages offered by cloud computing technologies which include: cloud technologies reduce hardware and maintenance cost, accessibility around the globe, reducing time to design, build and manage the system, we can potentially use several years worth of energy in literary a few hours; lower cost for data storage, searching and retrieval, no more spending on computer upgrades, Cloud provider allocates resources according to demand rather than assigning resources to particular clients, resources are scalable according to demand as per need, it provides users' elasticity in terms of increasing or decreasing the resources used, pay-as-per-use: cloud computing cost is calculated based on its usage, less IT Infrastructure cost, less software cost, increased computing power, unlimited storage capacity, improved compatibility between operating systems, increased data security, accessibility from a range of devices, portability of documents and easier group collaboration. Benefits of cloud computing in managing online examination system pointed out by [3] include, cloud computing platform deliver needed resources, lower costs of infrastructure, automatic and dynamic resource allocation, reducing time to design, build and manage the system.

\section{Related Work}

A brief resume of researches focusing on adopting cloud computing technology in managing online examination in education includes: Authors in [3] published Architecture of cloud computing based online examination system. They focused on the application of cloud computing in examination management and described the role of cloud computing service model in managing examination system. They described that PAAS (Platform as a Service) provides application development and deployment tools for developing the system, business intelligence for student performance and also integration and testing of the system, NaaS (Network as a Service) provide virtualization by using tools like VMware (virtualization software). IaaS (Infrastructure as a Service) is sensitive layer of cloud. It contains physical data centers where data like logging information, question pool and their answers, multimedia data and score of the candidate are stored. The application developer and cloud service provider have access to all the three layers of cloud architecture. Authors in [4] proposed architecture for online virtual subjective examination system based on Ubiquitous cloud. The proposed system targeted on the generation of virtual digitized written answer sheet. The system consists of entities like tablet, stylus, router, server and wireless fidelity (WiFi) communication network. In the proposed scenario students were provided with a tablet and a stylus to write on the virtual answer sheet after necessary authentication. The system was operated with three sets of user as Admin, supervisor, student. Admin create question papers. Supervisor distributes the question papers among the students in digital format. Students write on the virtual answer sheets. The authors also focused on role based access policy of admin, supervisor and student for the proposed system and presented security analysis for different issues which include authentication, storage of virtual answer sheet in the cloud, accessing the question papers, data exchange and transfer, and time parameter. In [5] authors proposed an effective framework for managing university data using a cloud based environment and developed cloud simulator on java platform using oracle $10 \mathrm{~g}$ for Jamia Millia Islamia University New Delhi, India. It has the following features (i) 


\section{International Journal of Science and Research (IJSR) \\ ISSN (Online): 2319-7064 \\ Index Copernicus Value (2013): 6.14 | Impact Factor (2015): 6.391}

support for modeling cloud computing infrastructure, which includes data centers containing university database ;( ii) a user friendly interface ; (iii) flexibility to switch between the different types of users ; and (iv) virtualized access to cloud data. In [6] authors assessed the potential advantage of cloud computing as a platform for e-learning. In their work they discussed that providing e-learning services using a cloudbased platform can reduce costs, can be easier to maintain and update, and offer benefits to end users in terms of security and compatibility. In [7] authors described the architecture of cloud computing platform by combining the features of e-learning and also described the benefits of the proposed architecture which include: powerful computing and storage capacity, high availability, high security and virtualization. In [8] presented e-learning ecosystem based on cloud computing infrastructure and also presented mechanisms which are mainly introduced by cloud computing infrastructure to guarantee the running of an elearning ecosystem. According to authors [8] and [9] cloud computing offer some potential solutions to overcome many of challenges which include: lack of a proper infrastructuremany organizations lack the proper infrastructure for adopting an E-Learning platform. A modern scalable infrastructure is needed as the creation of new content, which is often rich in multimedia, high resource requirements for aspects such as bandwidth and storage. Cloud technology can help overcome these challenges as the centralized infrastructure of a cloud system reduces the need to repeat tasks in each and every school where the system is deployed reducing the cost and time needed to build the infrastructure. Secondly, once a cloud is running in an organization, the deployment process is swift across the organization because of lack of technical work to deploy the services in individual schools. The third advantage is the lower cost of hardware infrastructure in individual schools, as often only computers with low specifications, capable of running a browser, can be used. Lack of curriculum-the lack of content that is ready to be imported into the E-Learning system is a common challenge that education institutions often face. Ideally, this needs to be planned up-front along with considerations of the infrastructure that is required. Cloud computing can enhance readiness in two key ways. The first is by providing an easy to use platform for teachers and students to access from anywhere there is a device with an internet connection. The second advantage is learning system is established the data needs to be updated and the hardware and software require routine maintenance. Many academic institutions do not have the competencies to support their own infrastructure and respond to issues such as network outages or security threats. Technical support time is reduced with a cloud based system because cloud technology utilizes a centralized infrastructure approach that reduces the need to spend time on issues such as service availability, and application compatibility by providing and delivering services through a browser. Change management-one of the biggest challenges of E-Learning is to manage the change process within the education organization, when moving to an online platform. The change affects all stakeholders of the organization, such as the students, educators, decision makers, content developers, and system support staff. Therefore forward planning is essential when implementing such a major change. The first benefit that clouds provide to the change management process is the quicker pace of deployment. With the use of clouds the e-learning system can be deployed and spread over the organization more quickly, and people are more likely to identify the value of the system and to realize they need to utilize it in their daily lives. The second benefit relates to the ease of access. Clouds enable wider accessibility as any system with internet access is able to access the learning platform. This allows educators and teachers to have access to the learning platform from their home, which gives them more ability to test and use the system. Consequently, if more time is spent on the system the resistance to change will be reduced in the organization.

\section{Challenges in Integrating Online Examination System}

The various challenges encountered while adopting online examination system pointed out by researchers in their work are as follows. The challenges in integrating ICT in examination system pointed out by [10] and [11] includes: lack of resources, lack of technology knowledge and skills, institutional barriers, attitudes and beliefs towards technology, lack of integrating technology in assessment process, lack of integrating technology in subject culture, lack of user friendly interface, lack of usability that affects the acceptance of e-examination, resistance of teachers to use technology, copy right issues, lack of time to create eassessment. Cloud computing is an excellent alternative for educational institutions which is especially under budget shortage to adopt online examination system without spending any more capital for the computers and network devices. In [12] authors identified the anticipated challenges in adapting ODES (On Demand Examination System) at the NOUN (National open University of Nigeria) which includes more investment is needed in the area of infrastructure and human development (ICT infrastructure, ICT skill development and training), lack of sufficient number of computers and room for installing them, appropriate software and adequate technology expertise are necessary for effective adaptation. Authors in [13] pointed out the key challenges in integrating examination system which include: non-availability of ICT infrastructure, resistance to adopt new technology, lack of motivational quality, frequent changes in administration which hamper the exploration and exploitation of ICT opportunities. In [14] authors have identified the various challenges encountered while adopting e-examination in the Nigeria educational system which include: lack of IT infrastructure, inadequate electricity supply, inadequate IT tools, inadequate questions in the question bank, and computer illiteracy. In [15] the authors pointed out the various problems associated with existing eexamination system in Nigeria. These problems include human interference, security issues, inadequate training for the students and staff and complexity of software. Authors [16] studied the challenges that are faced by an educational institute in integrating ICT tools in the learning process which include: refusing to learn new technology, misuse of ICT by students, teachers need to trained, availability to

Volume 5 Issue 4, April 2016 www.ijsr.net 


\section{International Journal of Science and Research (IJSR) \\ ISSN (Online): 2319-7064 \\ Index Copernicus Value (2013): 6.14 | Impact Factor (2015): 6.391}

house technology. In [17] the author have identified the various challenges while adopting online examination system which include: shifting the focus for preparation of eexamination (such as setting, scripting, uploading), time consuming and tiring, questions in question bank need to accessed and indexed, setting of viable physical and IT infrastructure to support examination, instituting policies and procedures to ensure the validity of e-examination, problem of technical failure on the day of examination. Study [18] has been commissioned by the National Institute for Smart Governance and prepared a roadmap for the Ministry of Human Resource and Development, India to introduce ICT in public schools in a mission mode and identified that service providers are facing a number of challenges in offering different products in schools which include: absence of basic infrastructural facilities like Electricity, Internet connectivity, language problem, resistance to use technology, lack of IT infrastructure, absence of qualified and trained personnel, managerial challenges and funds management issues. Authors [19] identified the challenges in implementing ICT in education system in the Jammu and Kashmir state, India which include: digital divide, lack of internet facility in rural areas, lack of ICT infrastructure in educational institutions, non-availability of skilled staff, lack of ICT trained teachers, lack of ICT awareness, lack of ICT tools operating skills, language problem, lack of coordination between private and government schools to share the resources. According to Authors [20] the reason for unsuccessful e-learning is the lack of completely trusted, secure and protected e-assessment.

\section{Proposed Cloud based Examination Management (CEM) Architecture}

To address the challenges pointed out by researchers in their work in adopting online examination in the educational institutions, cloud based Examination Management (CEM) architecture is proposed. The proposed architecture is inspired from [4] and [5]. Online examination cloud is a migration of cloud computing technology in the field of online examination, which provides all the necessary infrastructure, hardware and software computing resources engaging in online examination management. The proposed architecture is comprised of three layers: Exam cloud app user layer, Cloud service delivery layer and Cloud Service deployment layer.

\subsection{Description of proposed Cloud based Examination Management (CEM) Architecture}

\subsubsection{Exam Cloud App User Layer:}

Examination management application deployed on cloud can be accessed by users through web browser on-per-use-basis. The end-users in an examination usually consist of students, academic staff, administrative staff and Community. The end user use role-based services in the proposed cloud setup. In this layer role of students include: to register online, to fill examination form, to download syllabus, study materials, date sheet, hall tickets, progress report, apply to appear in online examination, attend online test, submit answers, know status of result, view declared results, apply for reevaluation, apply for certificates, submit grievances related to examination etc. The teachers role and responsibility in this layer include: to enroll and verify students detail, to upload student attendance, to redress the grievances of students and public, to track academic achievement and performance of students, online setting and uploading of subject wise question papers, to view the uploaded question papers, to upload staff details, to upload stream and subject wise detail of students, to upload detail of syllabus covered, to upload students details eligible for examination, detail of students not eligible for examination, session and section wise students detail and category wise detail, to view class wise/ subject wise results of students etc. The functionalities of admin include to verify the detail of students and staff, to provide login username and password to registered users, modify or delete the registered users, examination scheduling, appointing invigilators to supervise online examination, to upload orders, circulars and notification related to examination, postpone/cancel paper, re-scheduling examination, declaring results, issuing certificates, to monitor the students and staff during examination, track the performance of teachers and students, monitor the attendance of teachers and students, to view class wise/ subject wise detail, to view school wise result summary, handling all account matters, granting of school affiliation and accreditation. The roles and responsibilities of officials of examination conducting bodies include examination processing, allotting registration numbers, generating roll numbers, issuing roll no slips, preparation of hall-ticketadmission cards, preparing detail of examination center wise student detail, detail of center wise invigilators, preparing the dues of invigilators, evaluators, menial staff, processing of results, preparing school wise result details, subject wise result details, teachers' subject wise result detail, reviewing result detail and preparing detail of school type etc. The invigilator roles and responsibilities include: check hallticket, mark attendance, verify user login/password, conducting online exam, and prevent unfair practices and report any problem to admin occurring during examination. The community's role in this layer include, knowing the progress and result status of their wards, to know the attendance of the children, to know the academic achievement and performance of the child, submit the grievances, to know the academic achievement level of school, deposit online fee, download children admission form and apply for certificates etc.

\subsubsection{Cloud service delivery Layer}

This layer consists of various services provided by cloud provider which includes: IaaS (Infrastructure as as service), SaaS (Software as a Service), Platform as a Service (PaaS). SaaS (Software as a Service) is a model layer in which software and associated data are hosted on the cloud and provided to the end users. SaaS (Software as a Service) on cloud provides the various examination management services which include, Security as a service (SECaaS)-provide security solutions against threats, corruption and hacking. Data is provided through structured authentication with specific role and responsibility. It provides virtual network 


\section{International Journal of Science and Research (IJSR) \\ ISSN (Online): 2319-7064 \\ Index Copernicus Value (2013): 6.14 | Impact Factor (2015): 6.391}

(VPN) for additional security. Registration as a Service (RaaS)-provides registration facility to students, faculty members and assigns unique number to each candidate and faculty members. Question paper Management System as a Service (QMaaS)-provides the facility to teachers to manage questions in Question bank. From the question bank, the questions can be selected randomly and display one by one to the students on the day of examination. Monitoring as a Service (MaaS)-provides the facility to monitor the students and teachers on the day of examination. SMS as a Service (SMSaaS)-The cloud service provider provides the facility of sending and receiving-SMS. Interactive Voice Response System as a Service (IVRSaas)-provides automatic voice response system facility to users. Grievances handling as a Service (GHaaS) - provides the facility to handle grievance of the students and staff. Fee Management System as a Service (FMSaaS)-provides online fee payment facility. Result Management as a Service (RMaaS)- processes the examination results electronically. Some popular SaaS providers are Amazon C3, Amazon EC2, Rackspace files and cloud, gogrid, Microsoft azure. IaaS (Infrastructure as as service)-provides access to fundamental resources such as physical machines, virtual machines, virtual storage and network. Virtualization (VMwares) lets to run multiple virtual machines (VMs) on a single physical machine, sharing the resources of that single computer across multiple environments. Different virtual machines can run different operating systems and multiple applications on the same physical computer. Leading vendors that provide Infrastructure as a Service are Amazon Web Services, Go Grid, 3 Tera, Amazon Elastic Compute Cloud (EC2), Amazon S3, Rackspace Cloud Servers, Flexiscale and IBM Blue house or VMW. Platform as a service (PaaS) -provides computing platform to design, develop, build, test application and execute application on cloud environment. Application developers can develop and run their software solutions on a cloud platform without the cost and complexity of buying and managing the underlying hardware and software layers. PaaS produces a platform by integrating an cloud operating system (OS), middleware, application software and provides it as service. Azure, Google App engine, Netsuite, Force.com, OpSource, NaviSite, AT\&T are the examples of PaaS. The multiple software and hardware cloud components communicate with each other over application programming interfaces (APIs).

\subsubsection{Cloud service deployment layer}

The service deployment models of cloud computing include: 1) Public cloud-the public cloud offers IaaS , PaaS and SaaS as service. A public cloud is the obvious choice when: application is used by lot of people, the organization don't require high data security measures, need incremental capacity, to test and develop application code, doing collaboration projects, doing ad-hoc software development projects. For examination management in education public cloud can be used for those services where institutions don't require high data security measures. The popular public cloud service provider includes: Amazon EC2, S3, Google App Engine, and Force.com. 2) Private cloud deals the delivery of services to a restricted set of consumers, usually within a single organization. The primary purpose for implementing private cloud is to maximize and utilize existing in-house resources, data privacy and trust of security. Academic institutions build private cloud for examination management when security and data privacy are something of primary concern such as question paper management and evaluation processes. Popular examples of private cloud include Amazon Virtual Private Cloud (Amazon PVC), Eucalyptus platform, IBM Smart Cloud Foundation and Microsoft Private Cloud. 3) Hybrid cloud- is a combination of two or more clouds (private, community or public). The hybrid cloud use public cloud to interact with the clients and keep their data secured within private cloud. The organization use hybrid cloud to employ cloud bursting for scaling across clouds in which application runs in a private cloud and bursts to a public cloud when the demand for computing capacity increases. 4) Community cloud-It involves sharing of cloud computing infrastructure in between organizations involved in managing examination on cloud of the same community.

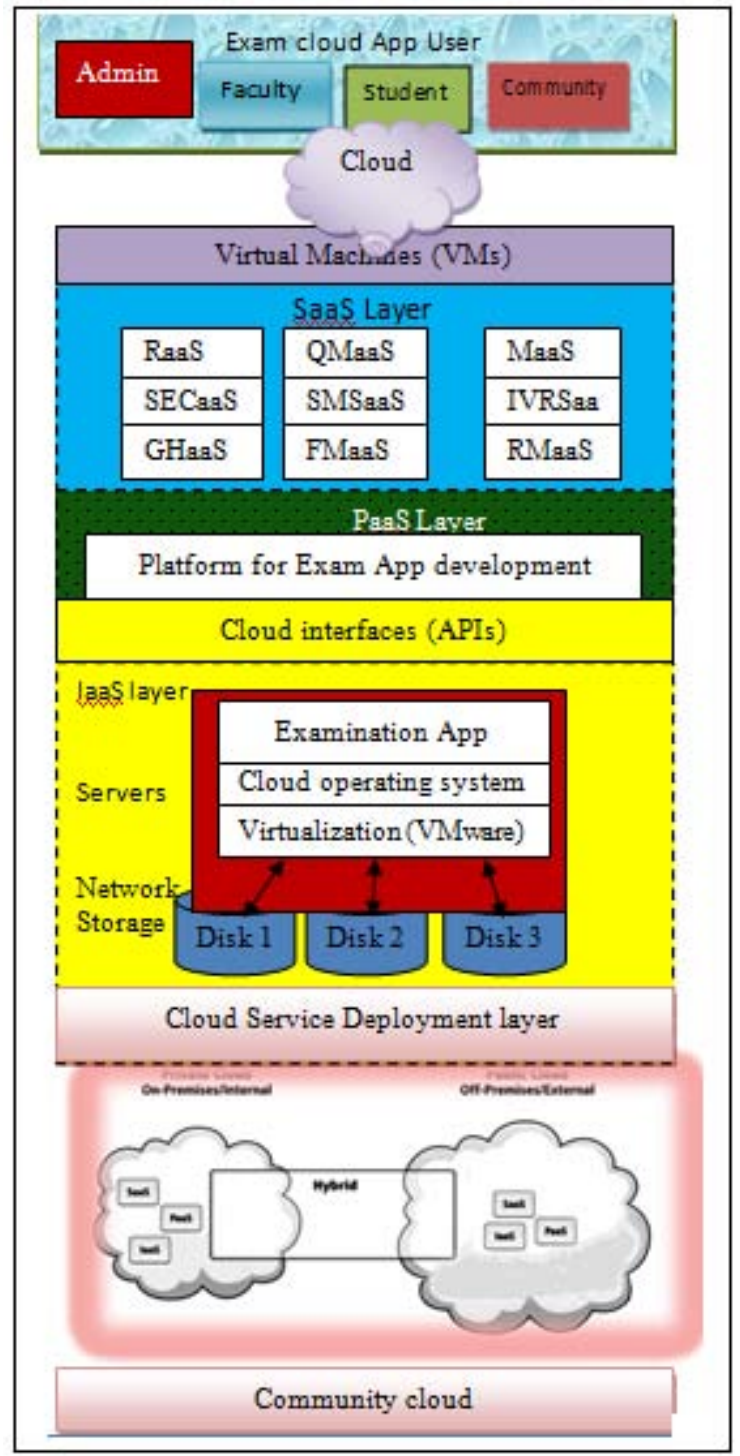

Figure: Components of Proposed Cloud based Examination Management (CEM) Architecture 


\section{The proposed steps for migrating existing resources to Cloud computing platform using open source cloud technologies are as under:}

- Install the open source virtualization software package on an existing host operating system (servers) as an application; this hosted application allows additional guest operating system to load and run with its own virtual environment e.g. Oracle VM VirtualBox is an open source virtualization software package which can be downloaded from https://www.virtualbox.org.

- Install Linux (Ubuntu), on virtual box.

- Install the open source cloud operating system that enables us to control large pools of compute, storage and networking resources e.g. Openstack is an open source cloud operating system that requires VM Virtual box and Devstack for its installation. Devstack can be down loaded from http://www.devstack.org.

- The implementation of the system requires the creation, execution and spinning up of virtual machine instances and virtual IP address for the pool by specifying detail requirements in openstack dashboard.

- In the physical servers (web services and database services), network equipment and their configurations are replaced by spinning up virtual instances running on the cloud.

\section{Benefits of migrating existing web based online examination management to cloud based online examination management are as follows}

- Optimum utilization of existing infrastructure: The government has already invested in core ICT infrastructure build-up. The Examination Cloud can initially be built on the existing infrastructure, or by its augmentation. Online examination cloud computing will enable optimum utilization of this infrastructure and reduce duplication of cost and effort.

- Rapid deployment and reusability: Applications developed by one entity (e.g. departments at the centre and states and private organizations) can be made available on online exam cloud. These applications can be deployed and re-used by other departments with the required customizations. As a result government departments will have the freedom to focus on their core objectives including policy, programs and process improvements or new applications development where a similar application does not already exist.

- Manageability and maintainability: The Exam Cloud will provide a single directory of services providing integrated visibility and control helping departments to dispense with the requirement of lengthy procurement and maintenance of ICT infrastructure, an exercise which many find difficult to perform.

- Scalability: Applications and infrastructure deployed on the common Cloud platform can take advantage of the virtualized nature of the cloud to scale as required. This essentially becomes more useful for applications where there is a burst of demand for ICT resources at regular intervals.

- Efficient service delivery and agility: Faced with the continued budget challenges all government departments need to find ways to deliver their services to citizens and business as economically as possible without compromising the achievement of desired outcomes. Easy and quick access to ICT resources will lead to a faster and more agile service delivery of citizen-centric services by the government.

- Security: A security as a service on Cloud will lead to less environmental complexity and less potential vulnerability. This will also help bring out the essential interoperability across various cloud environments.

- Cost reduction: The major advantage of the architecture is that it aims at providing easy access to costly software running on high performance processors to students at institutions which lack considerable facilities. The payper-use model of pricing in cloud will ensure that ICT resources and applications are made available without significant investment in infrastructure purchase and maintenance.

- Ease of first time IT solution deployment: Ease of procurement of software as a service provides an opportunity to agencies going for first time automation to leapfrog as they can buy services directly without going through the entire IT evolution cycle.

- Reduced effort in managing technology: Since most cloud offerings are based on prebuilt standardized foundation of technology that facilitates better support, Cloud will reduce government's effort in managing technology. Easy provisioning of computing resources will ensure more consistent technology upgrades and expedite fulfillment of IT resource requests.

- Powerful computing and storage capacity: Cloud based online examination architecture locates the computing and data in a large number of distributed computers, the sea of clouds in the tens of thousands of computers to provide powerful computing power and huge data storage space, puts the "cloud" as a service available to students via the Internet.

- Virtualization. Virtualization is the most important characteristics of this type of architecture. Each application deployment environment and physical platform is not related. It is managed, expensed, migrated, and backup through virtualization platform. It put the underlying hardware, including servers, storage and networking equipment, comprehensive virtualization, in order to build a resources pool of shared, distributed ondemand.

- Resource pooling: A cloud service provider's computing resources are 'pooled' to serve multiple consumers using either the multi-tenancy with physical model or the virtualization model, "with different virtual and physical resources assigned dynamically and on consumer demand it may reassigned". The pool-based computing paradigm lies in two important factors: economies of scale and specialization. The pool-based model result is that physical computing resources become 'invisible' to 


\section{International Journal of Science and Research (IJSR) \\ ISSN (Online): 2319-7064 \\ Index Copernicus Value (2013): 6.14 | Impact Factor (2015): 6.391}

consumers, in general who do not have control or knowledge over the location, formation, and originalities of these resources (e.g. database, CPU, etc.) Example of resources includes storage, processing, memory, network bandwidth, and virtual machines.

\section{Conclusions}

In this paper, we have proposed and discussed cloud based online examination management (CEM) architecture and also presented guidelines for managing existing resources for online examination adoption on cloud environment using open sources cloud technologies. The application of cloud computing technology to face the challenges encountered in the adoption of online examination system is a new idea and innovation which we have exposed in the educational system. The usage of cloud computing in examination management in education provide several benefits which include economic benefits, run applications on demand, location independent access to data , increased flexibility, elastic scalability, pay-as-you-go, easy to implement, service quality, update software automatically, and no maintenance costs etc.. During actual examination process number of students accesses the system and utilizes maximum processor and transactions during concurrent examination timing. Cloud computing can provide an option to utilize maximum resources during examination process and ramp down resources after examination is completed. Further studies may look at the implementation of proposed examination management architecture in managing online examination system and security issues associated with the adopting cloud based examination application in an educational institutions.

\section{References}

[1] G. Kaur, S. Chawla, "Cloud E Learning Application: Architecture and Framework," SSRG International Journal of Computer Science and Engineering, 1(4), pp. 1-5, 2014.

[2] M. Micheal, "Cloud computing: Web- based applications that change the way you work and collaborate online," USA: Que 2009.

[3] T. Prasad, A. Acharya, "An Architecture of Cloud Computing Based Online Examination System," International Journal of Computer Science and Technology, 3(2), pp.524-526, 2012.

[4] P. Deshpande, P. Sonone, G. Patil, A. Achari, "Online Virtual Subjective Examination System Based Under Ubiquitous Cloud," International Journal of Science and Research, 4(1), pp. 526-529, 2015.

[5] K. A. Shakil, S. Sethi, M. Alam, "An Effective Framework for Managing University Data Using a Cloud Based Environment," In Proceddings of $9^{\text {th }}$ National Conference INDIACom, pp. 8.60-8.65, 2015.

[6] F. Karim, R. Goodwin, "Using Cloud Computing in Elearning Systems," International Journal of Advanced Research in Computer Science \& Technology, 1(1), pp. 65-69, 2013.

[7] Md. A. H. Masud, X. Huang, “An E-learning System Architecture based on Cloud Computing," International
Journal of Computer, Electrical, Automation, Control and Information Engineering, 6(2), pp. 255-259, 2012.

[8] B. Dong, Q. Zheng, J. Yang, H. Li, M. Qiao, “An Elearning Ecosystem Based on Cloud Computing Infrastructure," In Proceedings of the Ninth IEEE International Conference on Advanced Learning Technologies 2009, pp.125-12, 2009.

[9] E. Aljenaa, F. Al-Anzi, M. Alshayeji, "Towards an efficient e-learning system based on cloud computing," In Proceedings of the Second Kuwait Conference on eServices and e-Systems 2011, ACM.

[10] M. Kuikka, M. Kitola, M-J. Laakso, "Challenges when introducing electronic exam," Research in Learning technology, 22, pp.1-10, 2014.

[11] K. F. Hew, T. Brush, "Integrating technology into K-12 teaching and learning: current knowledge gaps and recommendations for future research," Education Tech Research Dev (Springer), 2007.

[12] O. Adebayo, S. M. Abdulhamid, "E-Exams System for Nigerian Universities with Emphasis on Security and Result Integrity," International Journal of the Computer, the internet and Management, 18(2), pp.47.1-47.12.

[13] M. Bhardwaj, A. J. Singh, "E-Governance: Single portal for integrated Examination System," Emerging Technology in E-Government, G.P.Sahu, pp.288-293, 2008.

[14] Adegbija, M.A. Fakomogbon, F. O. Daramola, "The New Technologies and the conduct of E-Examinations: A Case Study of National Open University of Nigeria," British Journal of Sciences, 3(1), pp.59-66, 2012.

[15] M.V. Okonkwo, C. Akuadi, "Adapting on demand examination system in national open university of Nigeria end of semester examination," Turkish Online Journal of Distance Education, 12(4), pp.167-178, 2011.

[16] P. Samaya, C. Jose, V. Iyengar N. Ghag, "The Pros and Cons of Integrating ICT in an Educational Institution," In Proceedings of the $6^{\text {th }}$ National Conference INDIACom , 2012.

[17] J.Attewell, "Mobile technologies and learning," www.lsda.org.uk/files/PDF/041923RS.pdf. Federal Ministry of Education (2004). Ministerial initiative on eexamination for Nigerian education system. $e$-Education Project.

[18]Department of School Education \& Literacy, MHRD, Government of India, "Implementations in Government Schools-India," National Institute of Smart Governance report, India.

[19] V. Sharma, V. Mansotra, G.S. Sambyal, "Digital divide in Education-A concern for J\&K state," In Proceedings of the $3^{\text {rd }}$ National Conference INDIACom -2009, pp.73-78, 2009.

[20]K. M. Apampa, G. Wills, D. Argles, “ User security issues in summative e-assessment security," International Journal of Digital Society, 1( 2), 2010. 


\section{Author Profile}

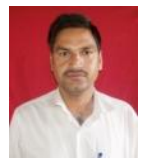

Jewan Sing is presently working as Lecturer in Computer Science in the School Education department Jammu and Kashmir Government, India and completed MCA from Kurukshetra University, Kurukshetra, India in 2004 and pursing Ph. D. from School of Electrical Engineering, Department of IT, AMET University,Tamilnadu, India. He has more than 14 years experience in teaching. He published and presented research papers in national, international conferences and journals. His research interests are in the field of, E-Governance, ICT, Education Technology, e-learning and Cloud computing.

Prof. Vibhakar Mansotra is presently working as Professor, Department of Computer Science \& IT, University of Jammu, J\&K, India. He received his Ph.

D. from University of Jammu, Jammu, India. He has more than 25 years of experience in teaching. He has published, reviewed and presented many research papers in national and international conferences and journals. His current interest includes cloud computing, data mining, information retrieval and eGovernance. 